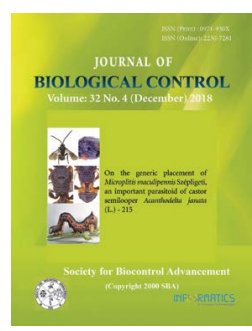

Research Article

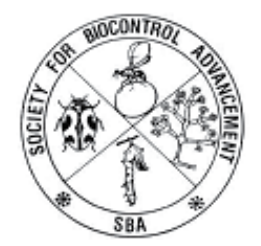

\title{
Morphology and performance specifications of Blaptosthethus pallescens Poppius (Heteroptera: Anthocoridae) when reared on two alternate laboratory hosts
}

\author{
TRIPTI GUPTA $^{\mathbf{1}^{*}}$, CHANDISH R. BALLAL ${ }^{2}$ and SHASHIKALA S. KADAM ${ }^{2}$ \\ ${ }^{1}$ Pest Control (India) Pvt. Ltd., Bio-Control Research Laboratories (BCRL), Arakere Post, Bengaluru - 562163, Karnataka, India \\ ${ }^{2}$ ICAR-National Bureau of Agricultural Insect Resources, H. A. Farm Post, Bellary Road, Bengaluru - 560024, Karnataka, India \\ ${ }^{*}$ Corresponding author E-mail: tripti123gupta@gmail.com
}

\begin{abstract}
The present research paper provides detailed morphology and morphometrics of an anthocorid predator, Blaptostethus pallescens Poppius. To identify the alternate laboratory host to be utilized for mass production, biological parameters of the anthocorid were evaluated by rearing on UV irradiated eggs of two alternate laboratory hosts, Corcyra cephalonica (Stainton) and Sitotroga cerealella (Motsch.). Five nymphal instars were recorded on both hosts. No significant differences were observed in incubation period, nymphal duration, total developmental period and sex ratio when reared on the two hosts. However, significant differences were observed in two biological parameters i.e., adult longevity and fecundity. Longer life span and higher fecundity of B. pallescens was recorded when reared on $C$. cephalonica eggs in comparison to $S$. cerealella eggs, indicating the suitability of $C$. cephalonica eggs for mass rearing $B$. pallescens in the laboratory. B. pallescens could be reared continuously for 7 generations on C. cephalonica eggs.
\end{abstract}

KEY WORDS: Blaptostethus pallescens, biological parameters, Corcyra cephalonica, fecundity, generations, incubation, morphology, morphometrics, Sitotroga cerealella

(Article chronicle: Received: 16-02-2018; Revised: 12-11-2018; Accepted: 15-12-2018)

\section{INTRODUCTION}

Pest management through utilization of chemical pesticides in agriculture is facing several obstacles including, development of pesticide resistance in pest population and human health hazards caused due to pesticide residues in food items. At this juncture biological control could emerge as an alternative method in controlling pests in different crop ecosystems. Several anthocorids species were reported to provide control several pests (Ballal and Yamada, 2016). Blaptostethus pallescens Poppius, a general predator with wide host range has been reported on maize, rose, castor, grapes, bamboo (Jalali and Singh, 2002; Ballal et al., 2003b; 2009; Gupta, 2009) in India. Blaptostethus pallescens has been identified as a potential bio-control agent for the management of eggs and larvae of lepidopteran pest, sucking pests like mites, thrips, mealybugs, aphids and stored insect pests (Ballal et al., 2009; 2012; Gupta and Ballal, 2011; Kaur and Singh, 2011; Sobhy et al., 2014; Lessando et al., 2015). However, natural population of this predator is insufficient to maintain the target pest population below economic injury levels on several crops. Therefore, mass production and augmentative releases of natural enemies may help to maintain some of the target pests below economic injury levels.
Knowledge on host acceptance behaviour and predatory potential of bio agents are prerequisites to optimise their mass production. Detailed information on morphometrics, biology and suitable alternative laboratory host for mass production are necessary to improve the utilization of this predator in biological control.

The objective of the present work was to study the morphology, morphometrics and biology to standardize an inexpensive production protocol utilizing an alternate laboratory host. We also aim to evaluate the effect of continuous laboratory rearing for several generations on the suitable and superior alternate laboratory host eggs.

\section{MATRIALS AND METHODS}

The study was conducted at the Mass Production Laboratory, National Bureau of Agricultural Insect Resources, Bengaluru. Morphology and morphometrics of $B$. pallescens egg, nymph and adult stages were studied by using ocular and stage micrometers. The biology of $B$. pallescens on two alternate laboratory host eggs Corcyra cephalonica (Stainton) and Sitotroga cerealella (Olivier) were studied under laboratory conditions $\left(26 \pm 2^{\circ} \mathrm{C}\right.$ and $55-65 \% \mathrm{RH})$. 
From the lab reared $B$. pallescens culture, five pairs of adults were released into each pearl pet plastic container $(500 \mathrm{ml})$. The containers were provided with UV-irradiated C. cephalonica eggs as feeding, bean pieces (4-5 per container) as ovipositional substrates and cotton lint to avoid cannibalism. Eight such sets were maintained. After every 24 hour period, the bean pieces with $B$. pallescens eggs were collected and observed under the microscope to record the number of eggs laid, after which they were placed in $500 \mathrm{ml}$ pearl pet containers for hatching.

Number of nymphs hatched from total eggs on the bean pieces in each container was counted for calculating percent hatching. Freshly hatched nymphs were kept individually in jewel boxes provided with UV-irradiated C. cephalonica eggs and observed daily to record total number of instars, duration of each instar and total nymphal period.

When adults emerged, they were collected and observed under microscope to differentiate the sex. Percent adults formed were calculated based on the number of healthy adults developed from the total number of nymphs recorded in each replication. Longevity of adult male and female was recorded. Same procedure was followed to study the biology of B. pallescens reared on S. cerealella eggs.

Generation-wise progeny production was studied by initiating the experiment with field collected adults of $B$. pallescens. The experiment was initiated with two females of $B$. pallescens collected from maize field per replication and replicated five times. The field collected adults were allowed to oviposit and the nymphs which hatched from the eggs were placed in a nymphal container. The progeny produced by the field-collected females in the laboratory was considered as the first laboratory generation. The adults belonging to the first laboratory generation were placed in an ovipositional container, which was provided with feeding (C. cephalonica eggs) and ovipositional substrate (bean pieces). This ovipositional container was marked as the first laboratory generation. Progeny produced by the adults of each generation were recorded and kept in separate ovipositional containers marked with the generation number. The progeny production per female and per cent increase per generation were also calculated and represented graphically.

\section{RESULTS AND DISCUSSION}

\section{Morphology and morphometrics}

Eggs are bottle shaped and creamy white with an operculum at the anterior end. The posterior end is oval and inserted inside the bean pod with only the operculum visible. Some eggs are laid tangential to the surface of bean pods. At the time of hatching, operculum opens like a lid. The mode of egg laying varies in different anthocorid species. Some anthocorid species require plant tissue for the oviposition, while some can lay on cotton strands, container walls, etc. Muraleedharan and Ananthakrishnan, (1978) reported that the eggs of Carayonocoris indicus Muraleedharan are inserted into the petiole of Cassia marginata L. Blaptostethus pallescens eggs are deposited singly with the operculum facing upward. Beans pods can be used successfully as ovipositional substrate for rearing $B$. pallescens (Ballal et al., 2003b; Sobhy et al., 2014). Kodakkadan Srikumar et al. (2017) reported that B. pallescens laid eggs on tea shoots. The average length, breadth of egg and diameter of operculum of B. pallescens egg are $0.82 \pm 0.02 \mathrm{~mm}, 0.38 \pm 0.00 \mathrm{~mm}$ and $0.25 \pm 0.25 \mathrm{~mm}$, respectively (Table 1 ).

Five nymphal instars were reported in present study. Morphological characteristics of each instar were as follows

a) First instar: Just after hatching, the head, thorax and posterior margin of abdomen is slightly pink in colour with dark red eyes. The rostrum is three segmented and pale yellow in colour. The antenna is four segmented and greyish in colour. Dark red scent glands are clearly visible on the $3^{\text {rd }}, 4^{\text {th }}$ and $5^{\text {th }}$ abdominal segments. Abdominal apex has long white bristles and legs are pale yellow in colour. The average length and greatest width $0.93 \pm 0.02$ and $0.38 \pm 0.00 \mathrm{~mm}$, respectively.

b) Second instar: Uniformly pink in colour. First antennal segment is transparent and the other three segments are greyish in colour. First and second antennal segments are stout and $3^{\text {rd }}$ and $4^{\text {th }}$ segments are slender and filiform. It measures $1.07 \pm 0.02 \mathrm{~mm}$ in length and $0.45 \pm 0.02 \mathrm{~mm}$ in width (greatest).

Table 1. Morphometrics of Blaptostethus pallescens

\begin{tabular}{|l|l|l|}
\hline Stage & Length $(\mathrm{mm})$ & Greatest width $(\mathrm{mm})$ \\
\hline Egg & $0.82 \pm 0.02$ & $0.38 \pm 0.0$ \\
\hline \multicolumn{2}{|l|}{ Nymphal instars } \\
\hline I & $0.93 \pm 0.02$ & $0.38 \pm 0.00$ \\
\hline II & $1.07 \pm 0.02$ & $0.45 \pm 0.02$ \\
\hline III & $1.66 \pm 0.06$ & $0.69 \pm 0.04$ \\
\hline IV & $1.97 \pm 0.11$ & $0.88 \pm 0.02$ \\
\hline V & $2.60 \pm 0.14$ & $0.90 \pm 0.02$ \\
\hline Adult & & \\
\hline Male & $2.70 \pm 0.06$ & $0.92 \pm 0.08$ \\
\hline Female & $2.90 \pm 0.24$ & $0.98 \pm 0.03$ \\
\hline
\end{tabular}




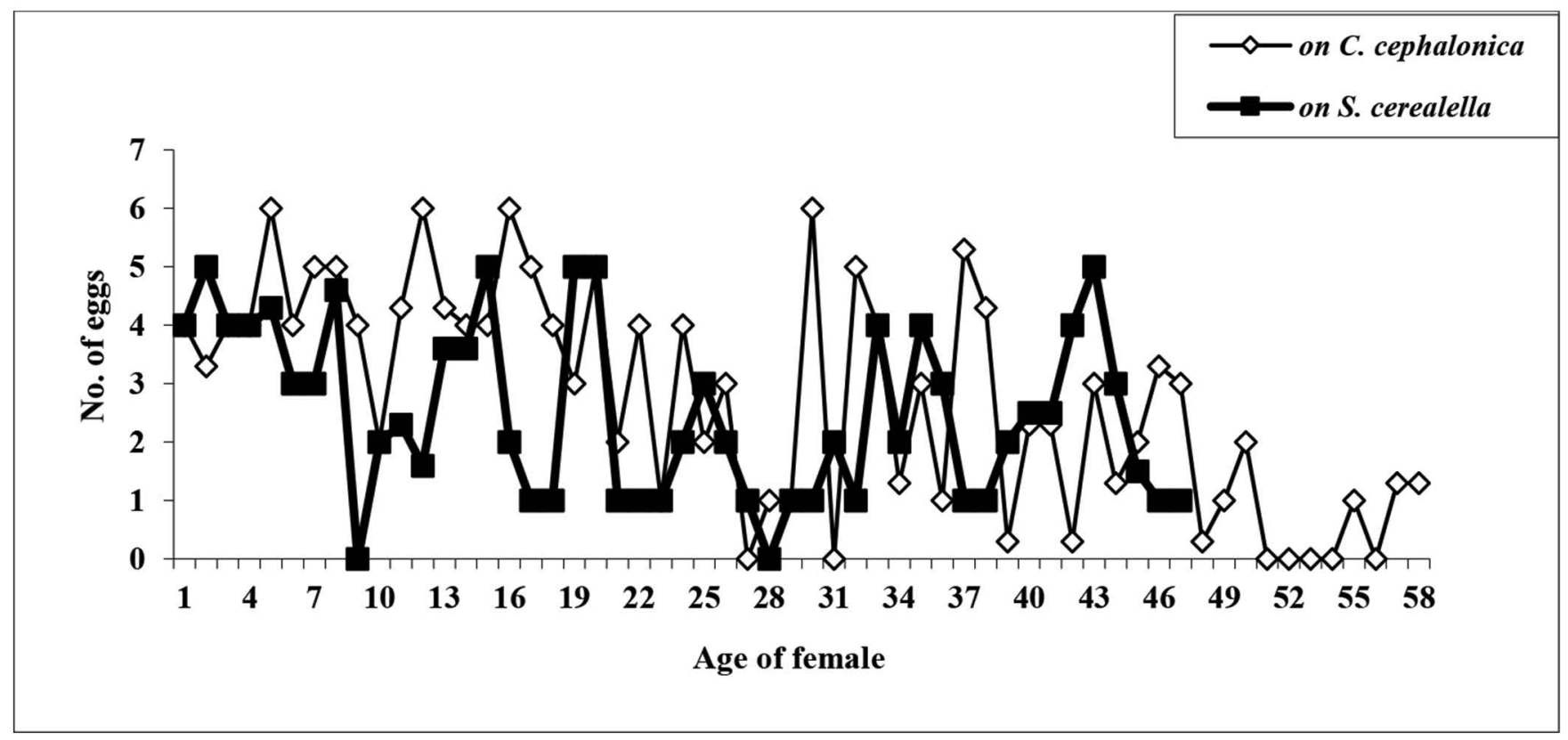

Fig. 1. Day wise fecundity of Blaptosthethus pallescens on two alternate laboratory host eggs.

c) Third instar: Acquires uniform reddish orange colour and is darker in colour than second instar. Wing pads are visible. Average length is $1.66 \pm 0.06 \mathrm{~mm}$ and greatest width $0.69 \pm 0.04 \mathrm{~mm}$.

d) Fourth instar: Body colour changes to dark reddish brown. Scent glands are not very distinct as in earlier instars. Wing pads are more developed. Length and greatest width measured $1.97 \pm 0.11$ and $0.88 \pm 0.02 \mathrm{~mm}$, respectively.

e) Fifth instar: Reddish blackin colour. Rostrum red. Wing pads extend beyond thorax. Basal antennal segment is darker than rest of the segments. Average length $2.6 \pm 0.14 \mathrm{~mm}$ and greatest width $1.0 \pm 0.02 \mathrm{~mm}$.

Tawfik and Husseini (1971), Ballal et al. (2003b), Sobhy et al. (2014) and Kodakkadan Srikumar et al. (2017) also reported five nymphal instars in B. pallescens. Muraleedharan and Ananthakrishnan (1978) reported five nymphal instars in anthocorid species like $C$. indicus, Montandoniolamoraguesi (Puton), Xylocoris clarus (Distant) and Scoloposcelis paralellus (Motschulsky).

Fifth instar moults to become adult which is black in colour with fully developed wings. Clear sexual dimorphism is visible in B. pallescens. Abdomen is broader in female, with two copulatory tubes. The tip of abdomen in male is slightly twisted towards its left side when observed ventrally. A bunch of setae are visible on dorsal side in both sexes. Fore femora is with 5-6 strong peg like teeth on distal side and fore tibiae with a lateral row of teeth almost throughout their length. Mid and hind tibiae are with irregular spines on the surface and more spines are present in the distal half. Female is larger than male. Similar observations were made by Rajasekhera (1973) in B. kumbi and Ballal et al. (2003b) in B. pallescens. Average length and greatest width of female is $2.9 \pm 0.24$ and $0.98 \pm 0.03 \mathrm{~mm}$, respectively and that of male $2.7 \pm 0.06$ $\mathrm{mm}$ and $0.92 \pm 0.08 \mathrm{~mm}$, respectively (Table 1 ).

\section{Comparative Biology of Blaptosthethus pallescens on Corcyra cephalonica and Sitotroga cerealella}

There was no significant difference in the incubation period of B. pallescens, when reared on C. cephalonica and $S$. cerealella host eggs. It ranged from 3-5 (mean 4.5 \pm 0.22 ) and 4-6 days (mean $4.60 \pm 0.33$ ), respectively (Table 2). There was no significant difference in the total nymphal period when fed on $S$. cerealella and $C$. cephalonica, mean values being $16.50 \pm 1.02$ and $16.3 \pm 0.62$ days, respectively (Table 2). Duration of first to fifth nymphal instars was observed to be $3.6 \pm 0.62,2.2 \pm 0.20,2.2 \pm 0.37,2.4 \pm 0.40$ and $6.0 \pm 0.55$ days, respectively (Table 3 ). First and fifth nymphal instars were recorded to be a longer nymphal duration which has also been reported by Sobhy et al. (2014) and Kodakkadan Srikumar et al., (2017).

No significant difference was observed in total developmental time of female and male when reared on C. cephalonica and S. cerealella eggs (Table 2). Female survived for a longer duration than male in both the treatments. 
Table 2. Comparative biology of Blaptosthethus pallescens on eggs of Sitotroga cerealella and Corcyra cephalonica

\begin{tabular}{|l|l|l|l|}
\hline \multirow{2}{*}{ Stage } & S. cerealella & C. cephalonica & $\begin{array}{l}\text { CD at } \\
\text { P } \leq 0.05\end{array}$ \\
\cline { 2 - 4 } & $\begin{array}{l}\text { Mean } \pm \text { SEM } \\
\text { (Range) }\end{array}$ & $\begin{array}{l}\text { Mean } \pm \text { SEM } \\
\text { (Range) }\end{array}$ & NS \\
\hline Egg period (days) & $4.60 \pm 0.33(4-6)$ & $4.5 \pm 0.22(3-5)$ & NS \\
\hline $\begin{array}{l}\text { Total nymphal Period } \\
\text { (days) }\end{array}$ & $16.50 \pm 1.02(14-20)$ & $16.3 \pm 0.62(14-16)$ & NS \\
\hline Male Developmental period & $23.00 \pm 1.52(20-25)$ & $21.0 \pm 0.50(21-20)$ & NS \\
\hline Female Developmental period & $19.60 \pm 0.03(19-20)$ & $19.8 \pm 2.30(15-23)$ & 4.05 \\
\hline Longevity male (days) & $31.25 \pm 2.05(26-32)$ & $42.4 \pm 5.82(38-68)$ & 4.77 \\
\hline Longevity female (days) & $47.40 \pm 4.55(36-58)$ & $58.2 \pm 5.06(44-78)$ & 30.09 \\
\hline Eggs/female & $91.25 \pm 8.43(74-109)$ & $132.8 \pm 22.4(84-199)$ & 8.67 \\
\hline Nymphs/female & $75.75 \pm 8.86(55-91)$ & $119.6 \pm 18.3(78-175)$ & 6.92 \\
\hline Adults/female & $58.50 \pm 8.70(40-82)$ & $100.4 \pm 17.46(67-160)$ & 2.65 \\
\hline Percent eggs hatched & $82.59 \pm 3.01(75-89)$ & $90.9 \pm 2.18(84.61-97.5)$ & NS \\
\hline $\begin{array}{l}\text { Percent adults developed from total number of } \\
\text { nymphs }\end{array}$ & $77.05 \pm 5.79(63-90)$ & $83.46 \pm 2.41(77.31-90.28)$ \\
\hline $\begin{array}{l}\text { Sex ratio (F: M) } \\
\text { (\% female) }\end{array}$ & $\begin{array}{l}1.44: 1 \\
(59)\end{array}$ & $\begin{array}{l}1.5: 1 \\
(60)\end{array}$ & NS \\
\hline
\end{tabular}

Table 3. Duration of nymphal instars of Blaptosthethus pallescens on Corcyra cephalonica eggs (the more suitable host)

\begin{tabular}{|c|c|c|}
\hline \multirow{2}{*}{ Instar } & \multicolumn{2}{|c|}{ Duration in days } \\
\cline { 2 - 3 } & Mean \pm SEM & Range \\
\hline I & $3.6 \pm 0.62$ & $2-6$ \\
\hline II & $2.2 \pm 0.20$ & $2-3$ \\
\hline III & $2.2 \pm 0.37$ & $2-3$ \\
\hline IV & $2.4 \pm 0.40$ & $2-4$ \\
\hline V & $6.0 \pm 0.55$ & $4-7$ \\
\hline
\end{tabular}

Longevity of adult female and male was significantly higher when reared on $C$. cephalonica eggs in comparison to when reared on $S$. cerealella eggs. On $C$. cephalonica eggs, female longevity ranged from 44-78 days (mean 58.2 \pm 5.06 ) and male longevity was 38-68 days (mean 42.4 \pm 5.82 ) (Table 2). When B. pallescens was provided with $S$. cerealella eggs, females lived for a mean of $47.40 \pm 4.55$ (range 36-58) and males survived for 31.25 \pm 2.05 (range 26-32) days. Longer life span of females in other anthocorid species like Cardiastethus exiguus Poppius and Orius tantillus (Motsch.) were also observed by Ballal et al. (2003a) and Gupta and Ballal (2006).

Adults mated just after emergence. Significant difference was observed in the number of eggs laid by a female when reared on $S$. cerealella eggs in comparison to that when reared on $C$. cephalonica eggs. Fecundity varied from 74-109 eggs per female (mean 91.25 \pm 8.43 ), when reared on eggs of S. cerealella and 84-199 eggs per female (mean 132.8 \pm 22.4 ), when reared on eggs of $C$. cephalonica. Egg laying was observed from the first day after mating and continued till mortality of the adult female. The number of eggs laid per day varied from 0 to 6 . Higher peaks were observed on $5^{\text {th }}, 12^{\text {th }}$, $16^{\text {th }}$ and $30^{\text {th }}$ day (approximately 6 eggs per day) when fed on C. cephalonica eggs (Fig. 1). Intermittently, zero progeny production was recorded. After 50 days, progeny production gradually reduced. When $S$. cerealella eggs were provided, higher peaks were observed on $2^{\text {nd }}, 15^{\text {th }}, 19^{\text {th }}, 20^{\text {th }}$ and $43^{\text {rd }}$ day.

Per cent hatching was 90.9 and $83.46 \%$ of nymphs formed adults when reared on $C$. cephalonica eggs. On $S$. cerealella eggs $82.59 \%$ eggs hatched and 77.05\% nymphs developed into adults. Sex ratio was 1.44: 1(Female: Male) on $S$. cerealella and on $C$. cephalonica 1.5:1.00 (Female: Male).A female biased sex ratio was recorded in B. pallescens when reared on both host eggs. This agrees with the studies of Tawfik and Husseini (1971) and Ballal et al. (2003b) who also observed percent female progeny was more than male. Generally a female biased sex ratio is considered to be positive attribute for a biological control agent, making it amenable to rearing in the insectary and a good field performer.

\section{Generation-wise progeny production of Blaptosthethus pallescens on UV-irradiated Corcyra cephalonica eggs}

When B. pallescens was reared on C. cephalonica eggs in the laboratory, seven generations could be reared in a period of nine months. Nine adults were produced in the first generation from one field collected B. pallescens female. Progeny production in the second generation was recorded 
as 13 adults per female. In the third generation there was an increase in total progeny production i.e., 126 adults but the percentage increase was only 62 . In the fourth, fifth and sixth generations, the progeny production increased by 67,90 and 127 percent respectively, with the number of progeny produced recorded as 211, 400 and 669 adults in the respective generations. In the seventh generation a total of 932 adults were produced but the percent increase was only 39 (Fig. 2). Almost six generations overlapped during the study period because of the prolonged longevity of the adult females. Progeny production was high in the first laboratory generation compared to the subsequent laboratory generations. Bio-deterioration in the laboratory cultures of parasitoids and predators was also observed by Penn et al. (1998), PDBC- ICAR (1999), Ballal et al. (2001; 2003a) on continuous laboratory rearing of Trichogramma parasitoids, Scymnus coccivora Ayyar, Campoletis chlorideae Uchida and Cardiastethus exiguus Poppius, respectively. Though the total number of adults obtained per generation kept increasing, the number of progeny produced per female ranged between 2.48- 4.46 from second to seventh laboratory generations (Fig. 2).

The remarkable increase in the total $B$. pallescens adults obtained from each production unit in each generation could be attributed to the high fecundity and longevity of B. pallescens on C. cephalonica eggs. However, the lower progeny production per female could be due to the rearing conditions provided and continuous rearing in confinement. This agrees with the statement of Boller (1972) that the role of insect behavior and its effects under selection in the insectaries is a major factor influencing the quality of reared insect.

Rearing of anthocorid predators on target hosts like thrips or mites may be extremely cumbersome. In the present study the biological parameters of $B$. pallescens, with high longevity and fecundity indicates that it is a potential bio agent which can be effectievly reared on eggs of alternate laboratory host $C$. cephalonica eggs. It was also observed that field collected $B$. pallescens could be reared successfully up to seven generations in the laboratory, rejuvenation of the laboratory culture may be required after seventh generations by bringing in the wild culture of the anthocorid predator from field and mixing with the lab culture.

\section{ACKNOWLEDGEMENTS}

The authors wish to thank Dr. Sunil Joshi, Principal Scientist and Dr. Y. Lalitha, Assistant Chief Technical Officer,

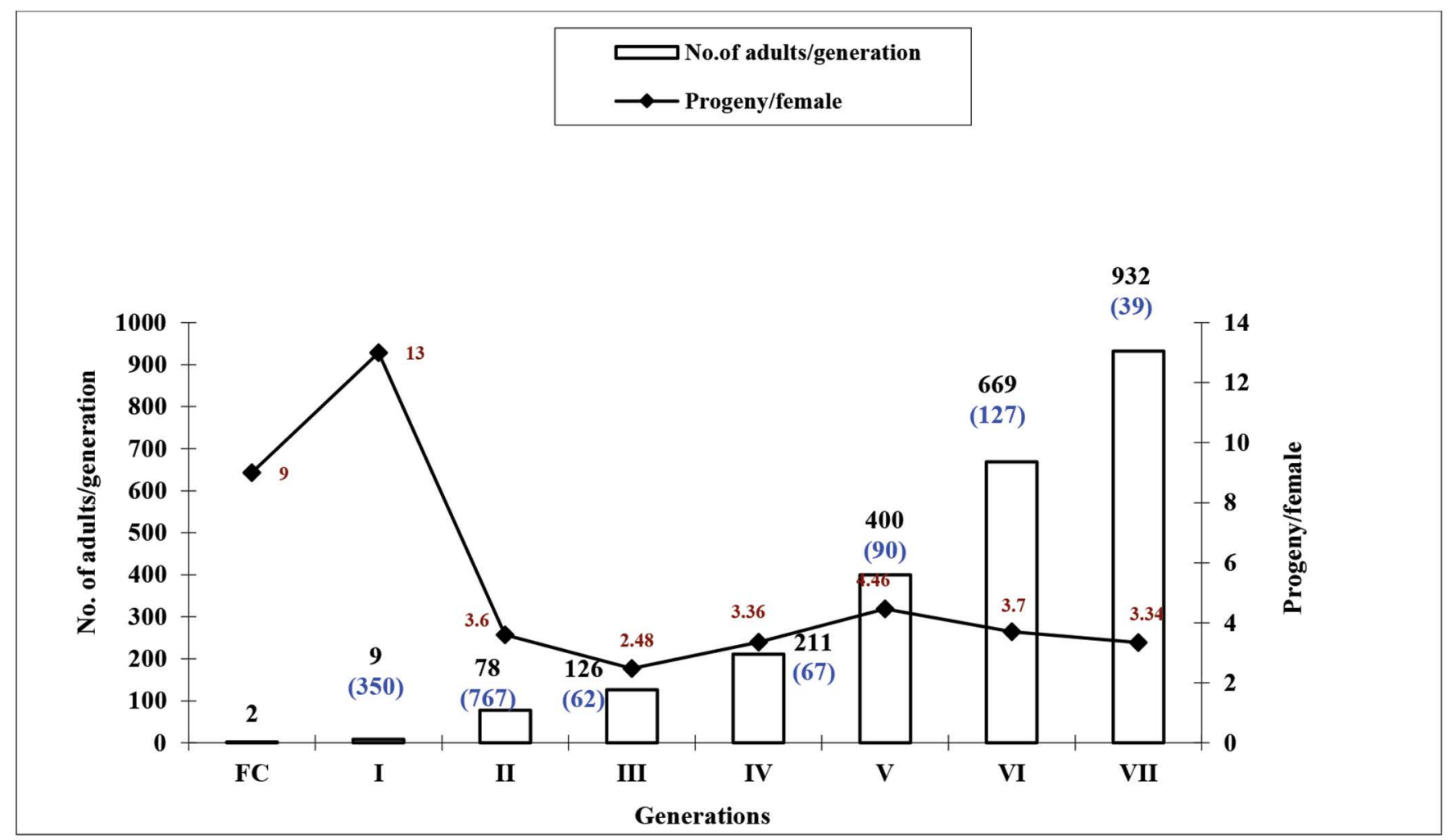

Fig. 2. Generation wise progeny production of Blaptosthethus pallescens on Corcyra cephalonica eggs (figures given in brackets are rate of increase/ decrease from the previous generation) 
ICAR-National Bureau of Agricultural Insect Resources, for the continuous supply of eggs of Sitotroga cerealella and Corcyra cephalonica for conducting the experiments.

\section{REFERENCES}

Ballal CR, Joshi S, Rao NS. 2001. Bio-deterioration of laboratory cultures of Campoletis chlorideae Uchida. pp. 257. In: Verghese A, Reddy RP (Eds.) IPM in Horticultural crops: Emerging trends in the New Millennium. Proceeding of the Second National Symposium on Integrated pest Management (IPM) in Horticultural Crops New molecules, Bio-pesticides and Environment. Bangalore, 257 pp. PMCid:PMC95474

Ballal CR, Singh SP, Poorani J, Tripti Gupta. 2003a. Feasibility of mass multiplication and utilization of Cardiastethus exiguus Poppius, a potential anthocorid predator of Opisina arenosella Walker (Lepidoptera: Oecophoridae). pp. 29-33. In: Tandon PL, Ballal CR., Jalali S. K. (Eds.). Biological Control of Lepidopteran pests, 354 pp. PMid:15025331

Ballal CR,Singh SP, Poorani J, GuptaT. 2003b. Biology and rearing requirements of an anthocorid predator, Blaptostethus pallescens Poppius (Heteroptera: Anthocoridae). J Biol Control 17: 29-33.

Ballal CR, GuptaT, Sunil Joshi, Chandrashekhar K. 2009. Evaluation of an anthocorid predator, Blaptostethus pallescens against two-spotted spider mite, Tetranychus urticae. Bull IOBC/WPRS 49: 127-132.

Ballal CR, GuptaT, JoshiS. 2012. Morphometry and biology of a new anthocorid Montandoniola indica, a potential predator of Gynaikothrips uzeli. Bull IOBC/WPRS 80: 79-84 pp.

Ballal CR, Yamada K.2016. Antocorid predator. In: pp. 329-366. Omkar (Ed.). Ecofriendly pest management for food security Elsevier, London 727pp.

BollerE. 1972. Behavioural aspects of mass-rearing of insects. Entomophaga 17(1): 9-25. https://doi.org/10.1007/ BF02371070

Kodakkadan Srikumar, Smitha S. Suresh kumar B, Radakrishnan B.2017. Biology and feeding efficacy of the anthocorid, Blaptostethus pallescens Poppius on Oligonychus coffeae in tea. J Biol Control 31(4): 198200. https://doi.org/10.18311/jbc/2017/18157
Gupta T, Ballal CR. 2006. Biology and Feeding Potential of an Anthocorid Predator, Orius tantillus (Motsch.) (Heteroptera: Anthocoridae) on Sitotroga cerealella. Ind J Plant Protect. 34(2): 168-172.

Gupta T. 2009. Studies on production and utility of anthocorid predators- with special reference to Orius spp. and Blaptostethus spp. Ph.D thesis submitted to Mysore University, 207.

Gupta T, Ballal CR. 2011. Preferential feeding potential of an anthocorid predator Blaptostethus pallescens Poppius on different stages of cotton mealybug. J Environ Entomol. 33(4): 423-428.

Jalali SK, Singh SP. 2002. Seasonal activity of stem borers and their natural enemies on fodder maize. Entomon 27(2): 137-146.

Kaur R, Singh VJ. 2011. Blaptostethus pallescens Poppius and Xylocoris flavipes (Reuter) in the suppression of Corcyra cephalonica Stainton in stored rice grain. J Biol Control 25(4): 329-332.

Lessando M. Gontijo, Daiane Celestino, Obiratanea S. Queiroz,Raul Narciso C. Guedes, Marcelo C. Picanço. 2015. Impacts of azadirachtin and chlorantraniliprole on the developmental stages of pirate bug predators (Hemiptera: Anthocoridae) of the tomato pinworm Tuta absoluta (Lepidoptera: Gelechiidae). Florida Entomologist 98(1). https://doi. org/10.1653/024.098.0111

Muraleedharan N, Ananthakrishnan TN. 1978. Bioecology of four species of Anthocoridae (Hemiptera: Insecta) predaceous on thrips, with key to genera of anthocorid from India. Ocassional paper. Records Zool Surv India 11: $1-32$.

Penn SL, Ridgway RL, Scriven GT, Inscoe MN. 1998. Quality assurance by the commercial producers of arthopod natural enemies. pp. 202-230. In: Ridgway RL, Hoffmann MP, Inscoe MN, Glenistar CS (Eds.). In: Mass reared natural enemies: Application, Regulation and Needs. Entomological Society of America, Baltimore, PDBC- ICAR.1999. Annual Report of the Project Directorate of Biological Control, Bangalore, 1998-99, $217 \mathrm{pp}$.

Sobhy I, Hamid AMA, Sarhan AA, Shoukry AA, Mandour NS, Reitz SR. 2014. Life history traits of Blaptostethus 
TRIPTI GUPTA et al.

pallescens (Hemiptera: Anthocoridae), a candidate for use in augmentative biological control in Egypt. Appl Entomol Zool. 49: 315-324. https://doi.org/10.1007/ s13355-014-0252-4
Tawfik MFS, El-Husseini MM. 1971. The life history of the anthocorid predator Blaptostethus piceus Fieber var. pallescens Poppius (Hemiptera: Anthocoridae). Bulletin de la Societe Entomologique d'Egypte 55: 239-252. 